\title{
Escribir sobre Eva. Victoria Ocampo y el ejemplar anotado de Eva Perón, ¿aventurera o militante?*
}

*Fecha de recepción: 6 de abril de 2015. Fecha de aceptación: marzo de 2016.

\section{Resumen}

Este trabajo indaga en las anotaciones manuscritas que la escritora Victoria Ocampo realizó en un ejemplar del ensayo de Juan José Sebreli, Eva Perón, ¿aventurera o militante? (1966), descubiertas recientemente en el archivo Ocampo y nunca divulgadas en su vida. Se trata de un hecho destacable, ya que no hay investigaciones o referencias sistemáticas de Ocampo sobre Evita, la popular primera dama del peronismo, contrafigura del perfil humanista y modernizador de Victoria. Este artículo explora la coyuntura política e intelectual en que se produjo este episodio, analiza los cruces ideológicos y culturales entre Eva y Victoria, e inquiere en la modalidad de sobreescritura como una estrategia que da cuenta de las transformaciones del campo cultural argentino durante la década de 1960.

\footnotetext{
Abstract

This paper investigates the Victoria Ocampo's handwritten annotations made in a copy of the Juan José Sebreli essay, Eva Perón, adventurer or militant? (1966) recently discovered in Ocampo's archive and never released during her lifetime. It is a remarkable fact, because there are no written or systematic references about Evita-the popular Peronist First Lady-in Ocampo's writings. According to this fact, the article explores the political and intellectual situations that occurred in this episode; discusses the ideological and cultural crossings between Eva and Victoria; and inquiries into the mode of overwriting as a strategy that reveals the changes into Argentine cultural field during the 1960 .
}

Palabras clave:

Eva Perón, Victoria Ocampo, Juan José Sebreli, Revista Sur, cultura argentina.

Keywords:

Eva Perón, Victoria Ocampo, Juan José Sebreli, Sur magazine, Argentine culture. 
1 Respecto de este hallazgo, ver la nota de Nicolás Helft y el artículo de Juan José Sebreli publicados en el suplemento adn del diario La Nación el 8 de julio de 2011.

2 En la bibliografía se encuentran referidas las intervenciones de Juan José Sebreli en la revista Sur.
1-A principios de 1966, Juan José Sebreli le envió un ejemplar de su nuevo ensayo Eva Perón, ¿aventurera o militante? a Victoria Ocampo. En una de las primeras páginas, con una caligrafía refinada, escribió: "Para Victoria Ocampo, este homenaje a una mujer argentina". Ella no respondió al regalo ni a la dedicatoria -una clara provocación-, ni encargó ninguna reseña para las páginas de Sur, la revista que ella dirigía. Nada dijo ni escribió al respecto y el libro con su dedicatoria fue a parar, entre otros tantos que recibía, a algún estante de su biblioteca.

Un hallazgo reciente en el archivo de Villa Ocampo, ${ }^{1}$ señala que, además del libro firmado por el ensayista, había otro ejemplar de Eva Perón, ¿aventurera o militante? subrayado en un tercio de las páginas y con numerosos comentarios manuscritos en los márgenes, todos ellos realizados con color rojo, el mismo que utilizaba Ocampo en muchos de los libros que leía con interés. En otras palabras, Victoria acogió el libro sobre Eva Perón firmado por Sebreli. Pero no fue el de la maliciosa dedicatoria el que tomó en sus manos y anotó con su lápiz rojo. En cambio, antes o después de que al ensayista se le ocurriera mandarle su nuevo libro, Victoria lo consiguió, lo leyó y lo anotó. Como puede verse en este ejemplar, cada intervención contradice manifiestamente la construcción que Sebreli elaboró sobre Evita. "Demostró tener la moral de una prostituta, incluso si no lo era", escribió Victoria, por ejemplo, en la página 52 como contestación a una línea elogiosa de Sebreli. En la página 82, frente a una cita de La razón de mi vida que desprecia el movimiento feminista, anotó: "El movimiento femenino es justicia social".

La relación entre Juan José Sebreli, por entonces de treinta y seis años, y Victoria Ocampo, de setenta y seis, estaba lesionada, justamente, a causa de las diferencias que ambos habían tenido respecto del peronismo. Sebreli había publicado una docena de textos en la revista Sur entre 1952 y 1955: reseñas de libros, críticas cinematográficas y ensayos. ${ }^{2}$ Entre ellos se encontraba el artículo "Celeste y colorado"(noviembre de 1952), que tuvo una buena acogida en el medio intelectual de aquel momento. En él se recorrían dos líneas antagónicas que atravesaban la historia argentina y que se actualizaban en la puja entre el peronismo y el antiperonismo. Frente a esta dicotomía y a cualquier noción de "idealismo político", el texto planteaba, en cambio, la opción por el compromiso y la superación dialéctica de esas facciones. La publicación de este texto significaba una audacia para los márgenes ideológicos de la revista e implicaba una apertura de Sur hacia el desafío político y cultural que encarnaba el peronismo. Fue en ocasión de las buenas repercusiones que tuvo "Celeste y colorado" cuando Victoria quiso conocer a al joven escritor. En su autobiografía El tiempo de una vida, Sebreli recuerda con algo de humor aquel encuentro: "Un día que habíamos ido con Héctor [Angeli] a llevar nuestras colaboraciones a Sur, Bianco nos hizo pasar al escritorio de la directora. La timidez frente al monstruo sagrado inhibió nuestra conversación. Oculta tras sus anteojos negros con armazón blanco nos observaba; es probable que nos tomara por amantes porque casualmente llevábamos la misma corbata-de moda en esa temporada- de estridente color anaranjado. Le dijo a Héctor que se parecía a Rimbaud. Pepe Bianco me contó después que, siguiendo su costumbre de buscar parecidos de personas con animales, había dicho que yo tenía los ojos más grandes que la cara, como una mosca". (Sebreli, 2005: 179).

La ruptura vino poco después, cuando Sebreli manifestó su simpatía hacia el gobierno en un medio vivamente antiperonista como era el que rodeaba a Sur. Ténganse en cuenta las diferencias que se habían abierto entre el movimiento político y Victoria Ocampo, sindicada, atacada y, a menudo, caricaturizada como el ejemplo mayor de la oligarquía, actor antagónico de los discursos oficiales. No se trataba solo de diatribas que se lanzaban desde el gobierno o desde la revista Sur: la misma Victoria Ocampo fue detenida y luego encerrada en la cárcel del Buen Pastor entre el 8 de mayo y el 
2 de junio de 1953, sospechada de participar en actividades conspirativas (Vázquez, 1991). ${ }^{3}$ A partir de este episodio no había espacio para grises.

El quiebre definitivo entre Sebreli y Ocampo fue la inclusión de una reseña de la novela Las arenas de Miguel Ángel Speroni en Sur en junio de 1955. Allí Sebreli, entre Arlt y Sartre, destacaba la unión de unos personajes alienados y resentidos para realizar una revuelta social, imagen que remitía, visiblemente, a una lectura revolucionaria del peronismo. Victoria, enterada de lo que su propia revista había publicado, reaccionó de inmediato. Escribe Sebreli en su autobiografía: "Furiosa, V.O. me mandó llamar y en su escritorio tuvimos una larga y acalorada discusión sobre el peronismo, donde lo defendí con buenos argumentos, pero con premisas falsas que me llevaban a conclusiones equivocadas. El disturbio tuvo sus consecuencias: [José] Bianco retiró de imprenta un artículo mío y me devolvió los originales, no ya en Sur sino en la confitería Jockey, para señalar las distancias". (Sebreli, 2005: 180)

Desde ese momento, y con el peronismo como brecha, la relación con Victoria se resintió. Sebreli la atacó en su exitoso ensayo Buenos Aires, vida cotidiana y alienación $(1964)^{4}$ y más adelante en el volumen Los oligarcas (1971), en los que la describía como apologista de las relaciones de dominación entre clases y la proponía como marca y seña del viejo patriciado en declive. Según el propio Sebreli, en varias ocasiones Victoria le enviaba a través de algún emisario notas manuscritas "con letra nerviosa" (Sebreli, 2005:180) indicándole algún dato o comentando irónicamente algunos de estos ataques. A ello se refiere María Esther Vázquez en su biografía sobre Ocampo: En 1965, Victoria -que tenía sus más y sus menos con Juan José Sebreli-, en una nota en la que hace referencia a la vaca que sus padres llevaban en el barco a Europa cuando ella y sus hermanas eran chicas para darles leche fresca, añade: "Esto de las vacas es un dato que le paso complacida, a Sebreli para su próximo best-seller". (Vázquez, 1991: 194)

En el marco de esta escalada, la dedicatoria manuscrita en Eva Perón, ¿aventurera o militante? ("Este homenaje a una mujer argentina"), más las alusiones hacia ella en el interior del libro, eran una clara afrenta que tenía como finalidad irritar a Ocampo. "Más molesto le habrá resultado que osara compararla en mi libro Eva Perón, ¿aventurera o militante? con una mujer a quien ella consideraba una enemiga" apunta Sebreli en El tiempo de una vida (Sebreli, 2005: 180). Y luego, en Comediantes y mártires comenta: "Mis relaciones con Victoria se enturbiaron aún más cuando en Eva Perón tracé un paralelismo entre la vida de ambas mujeres". (Sebreli, 2008, p. IV). Y sin embargo, Victoria pareció no responder a la provocación de Sebreli. En ocasión del descubrimiento del ejemplar con anotaciones en Villa Ocampo, Sebreli (2011) indicó que Victoria seguramente dudaba que él fuera el remitente de tal dedicatoria. Frente a la insolencia o el anonimato, Victoria prefirió otro ejemplar para realizar sus anotaciones.

2-Eva Perón, ¿aventurera o militante? puede considerarse un hito dentro de las relecturas (o de las rescrituras) de la izquierda sobre la figura de Evita (y en otros casos del peronismo) durante la década de 1960. En esta línea, la actriz malograda, la señora frívola, la mártir peronista o la tirana, según la facción que la considerara, era también la semilla y la promesa de un cambio social y político. ${ }^{5}$

Andrés Avellaneda (2002) señala que la introducción de la figura de Evita en la ficción durante la década de 1960 puede verse como un intento de revertir el modelo borgeano de "El simulacro" (1960), relato del cual se desprendía la imagen de un peronismo (y en particular de Evita) como una fachada demagógica y vacía montada alrededor de un cadáver. En contraposición, narraciones como "Señora muerta" (1963) de David Viñas y "Esa mujer" (1965) de Rodolfo Walsh, advierten, evitando cualquier pensamiento
3 La detención de Victoria Ocampo y de otras figuras opositoras se produjo luego de que, durante una concentración de qua durante una 15 de abril de 1953 en apoyo a Perón, 15 de abril de 1953 en apoyo a Perón
dos bombas provocaran varias muertes. Esa misma noche, grupos de militantes enfurecidos, incendiaron algunos edificios identificados con la oposición como la Casa del Pueblo (socialista), la sede del Partido Radical, el jockey Club y otros.

4 Aun así, Sur publicó una reseña positiva de Buenos Aires, vida cotidiana y alienación, firmada por Aldo Prior (1964).
5 De allí que entre todas esas facciones del mito evitista, durante los sesenta prevaleciera la imagen de una Eva jovial y sencilla, desprendida de sus atuendos glamorosos y de sus facciones dramáticas. Señala al respecto Beatriz Sarlo en su ensayo La pasión y la excepción: "El evitismo juvenil revolucionario de los años que vendrán, donde se cantó que 'si Evita viviera sería montonera', recogió esta iconografía porque encontró en ella dos temas: la juventud transparente y el vigor de la voluntad política contra todos los obstáculos." (Sarlo, 2003: 108) 
6 Américo Ghioldi escribía virulentamente en su ensayo dedicado a Evita (1956): “Todo lo que Eva Perón es resulta del poder dictatorial. No hay ningún aporte personal. Un 'robot' electrónico hubiera cumplido parecidas funciones [...] El poder le asignó un estado mayor de estrategia, una cierta capacidad de materia gris alqui-

lada, un equipo de administradores, lada, un equipo de administradores,
periodistas, fotógrafos, peinadores y modistas. El poder le dio mando para ejercerlo con capricho que, por lo demás, nunca le faltó." (Ghioldi, 1956: 52). Más adelante alimentaba el ideario de una mujer sin ningún atributo una autómata, sino como una bárbara: "Corta de inteligencia, deficiente de cultura y sensibilidad femenina, ignorante de las relaciones morales y civiles de los hombres, sin autocrítica, sin carga de escrúpulos de conciencia Eva Perón ingresa a la historia como una leyenda plantada en el mentidero argentino." (Ghioldi, 1956: 54).

7 En 1965 (es decir, un año antes de que saliera el libro sobre Eva Perón) ese prólogo fue incluido en Problemas del Marxismo I de Sartre. sobre la puesta en escena, que en ese cuerpo muerto se condensaban los imaginarios, las perspectivas y las contiendas sociopolíticas del presente y del futuro.

De modo paralelo, los ensayos que se acercaron a Eva en esta década parecían una reversión de mucha de la literatura antiperonista que se editó alrededor del golpe de 1955. En particular, varios de estos textos pueden considerarse como contrapartida de todos aquellos que desacreditaron su figura, desde la exitosa biografía La mujer del látigo de Mary Main, a Eva la predestinada de Román Lombille. Entre estos, estaba El mito de Eva Duarte, ensayo del socialista Américo Ghioldi (editado en 1952 en Montevideo, publicado en Buenos Aires en 1956), que describía a Evita como simple producto de una maquinaria estatal y mediática, de modo que su figura era solo un recipiente vacío, un robot asistido y manipulado por el Estado peronista - un argumento que se acercaba a la imaginación del simulacro borgeano- ${ }^{6}$ Con esta imagen Ghioldi pareciera estar recordando la autómata vamp del film Metrópolis (1927), en el cual una mujer robot es utilizada para manipular a las masas y crear caos social. En relación con esta construcción, Andreas Huyssen (2006) ha señalado, respecto del film de Fritz Lang, la asociación de la tecnología, la masa y la mujer como un otro amenazante que debe ser dominado: el robot es aprehendido y quemado por una multitud enardecida.

Frente a estos textos, el gesto de un intelectual que se quería de izquierda como Sebreli fue recuperar e inscribir a Eva dentro de un trayecto de transformación sociopolítica. Para esto, Eva Perón, ¿aventurera o militante? construye una figura que es superadora del peronismo (aunque no por ello exenta de contradicciones), a la vez que toma distancia del devocionario popular del movimiento. Por esta razón, titula "Eva Perón" y no "Evita".

La lectura del peronismo como inicio de una revolución pendiente y del lugar que la misma Eva Perón tuvo dentro de esa transformación ya había sido sostenido por Sebreli en su artículo "Aventura y revolución peronista" anunciado como parte de un libro que llevaría ese título y publicado en Contorno $n^{\circ}$ 7-8 (julio de 1956). En este texto, Sebreli encomiaba que La razón de mi vida pusiera en cuestión (aunque limitadamente) el orden clasista y patriarcal, la disciplina escolar y la sumisión de la mujer a las tareas domésticas. Asimismo, subrayaba que el mismo Perón, demagógico y cesarista, había iniciado a los obreros en su propia emancipación: "Perón mentía a los obreros haciéndoles creer que ellos eran el gobierno, cuando en verdad no lo eran. Pero la cara visible de esa mentira estaba en que los obreros se fueron familiarizando con la idea de que ellos debían y podían ser el gobierno, de que el gobierno era asunto de ellos. Por eso el peronismo no ha sido el sucedáneo de la revolución social sino su propedéutica..." (Sebreli, 1956: 49). En este sentido, si bien se aceptaba la línea del peronismo como artificio, se reconocía que tal acción iniciaba a los trabajadores y a otros grupos en la lucha política.

Once años después, una idea semejante del peronismo como iniciación de la revolución se ancló en la figura de Eva Perón tensada entre los términos de la aventurera y de la militante. Ambos conceptos eran por esta época una referencia obligada hacia el debate abierto por Jean-Paul Sartre (1950) en el prólogo al libro Retrato del aventurero de Roger Stéphane que tuvo una importante circulación durante la década de 1960 entre grupos de izquierda en América Latina. ${ }^{7}$ En este texto, Sartre diferencia los intereses y las motivaciones que movilizan al aventurero del militante. De este destaca su obediencia al partido, su lucha constante por un fin que trasciende lo inmediato y su renuncia al yo (o en todo caso la formulación de un nuevo yo dentro de la causa). El aventurero, por lo contrario, heredero de los vicios de la burguesía, tiene ambiciones individuales; es un héroe: busca construir un yo negando a la sociedad. Por esta causa se aleja de ella, quiere estar solo, distinguirse. Pero a diferencia de otras "soledades" 
burguesas, la del aventurero es virtuosa. Este se realiza a sí mismo a través de la acción. El aventurero no tiene como finalidad la revolución, sino su propia acción en el mundo y, en consecuencia, en su horizonte está la muerte, pues se hace consciente del fracaso inevitable de su empresa. Dadas estas condiciones, militante y aventurero confraternizan en la derrota. Sartre, en la derrota, prefiere al aventurero, "viviendo para morir y muriendo para vivir" (Sartre, 1965: 15). Los militantes, en todo caso, deben acoger el legado de las virtudes aventureras. No hay oposición entre ambos términos: dialécticamente, uno es la negación, el otro la afirmación. Por esta razón Sartre señala: Una ciudad socialista donde los futuros Lawrence fuesen radicalmente imposibles, me parecería esterilizada. E incluso si Lawrence a los ojos de los socialistas, fuese el Mal, sostengo que el fin no debe ser suprimir el Mal sino conservarlo en el Bien". (Sartre, 1965: 16) Sartre se refiere a T. E. Lawrence (Stéphane lo estudia en su libro), quien había sido traducido y publicado por la editorial Sur, y quien era una de las personalidades políticas e intelectuales más admiradas por Victoria Ocampo. ${ }^{8}$

En Eva Perón, ¿Aventurera o militante? Sebreli, apuntalado por conceptos sociológicos, existenciales y psicoanalíticos, ${ }^{9}$ recorre tres metamorfosis sufridas por Eva Perón ("La actriz", "La señora", "La compañera Evita") que la conducen desde el empoderamiento personal hacia la proyección de un cambio sociopolítico en el marco de un proceso revolucionario en el continente. El ensayo destaca, así, que Eva transforma sus motivaciones iniciales (el resentimiento, la ambición, el "ansia de inmortalidad") en vehículo de transformación para la clase obrera argentina: “...su subjetividad la lleva a la percepción objetiva de la situación de opresión de la clase obrera, por lo que finalmente los objetivos racionales y objetivos trascienden los móviles pasionales y dan libre y conscientemente el auténtico significado al acontecimiento histórico". (Sebreli, 1966: 90). La aventurera da paso así a la militante: Eva Perón -"sin quererlo" dice Sebreli- inicia la emancipación de los trabajadores y por ello es punta de lanza de una revolución pendiente.

Mención aparte merece la singular apreciación de la condición de mujer y la construcción de una sexualidad disidente de Eva Perón como matriz de transformación política que contrasta con la contrafigura burguesa de Victoria Ocampo -el libro está dedicado a Simone de Beauvoir- ${ }^{10}$ Sebreli sostiene que, a diferencia de muchas de las mujeres "auténticamente revolucionarias" como Flora Tristán y Rosa Luxemburgo, Evita, en su papel de "señora", se alimenta políticamente de su esposo, Perón. Cuando se metamorfosea en la "compañera Evita", se "masculiniza": su voz se vuelve "áspera" y se "ahueca", su puño se cierra, su vestimenta se vuelve gris y uniforme, sus gestos se tornan "agresivos". Evita, como ocurre con otras mujeres "en acción", dice Sebreli, impone una sexualidad "viriloide" y "clitoriana" que rechaza la condición pasiva de la mujer burguesa. Evita, en tanto "militante", al hacerse consciente de su cuerpo (lo que significa disolver su rol de "señora"), y de su acción en el mundo, se transforma en un medio de emancipación de los oprimidos.

Es interesante que, al mismo tiempo que Sebreli escribía Eva Perón, caventurera o militante?, el narrador y crítico David Viñas también estaba gestando un libro propio sobre la figura de Evita, hecho que da cuenta del interés de su figura de una parte del arco intelectual de la izquierda. Pero Sebreli se adelantó e hizo que Viñas (que venía pregonando acerca de su libro en distintos medios gráficos) lo abandonara. En julio de 1965 la revista Confirmado publicó una entrevista al ex director de Contorno en la que anunciaba la pronta aparición de un libro sobre Evita, en el que trabajaba desde 1962. Al principio, según la revista, Viñas había buscado financiación en la CGT (Confederación General del Trabajo, tradicionalmente de filiación peronista). Sin embargo quien terminó pagándole mensualmente para elaborar el libro en el que realizaría una "interpretación marxista de Eva Perón" fue el editor Jorge Álvarez. En esa misma entrevista, entre otras cosas, Viñas decía identificarse con Evita: "Somos
8 T. E. Lawrence fue una figura que revestía sumo interés para Victoria Ocampo. Muestra de ello son los dos libros que le dedicó: 338171 TE (1942) y Lawrence de Arabia y otros ensayos (1951). El primero fue traducido al francés (Gallimard, 1947) y al inglés (Gallancz, 1963). Además de publicar en 1944 el libro más difundido de Lawrence, Los siete pilares de la sabiduría, Ocampo tradujo El troquel (1955) para su editorial. En las cartas que le envió a Martínez Estrada (ver Epistolario, 2013), Victoria se refiere más de una vez a las dificultades que le ocasionaba esta traducción. Asimismo, en sus Testimonios pueden encontrarse varios textos dedicados al aventurero inglés: "El claustro de T. E. Lawrence" (1963), "Propósitos de Lawrence de Arabia" (1967) y "Am Sam Dram (El enigma de 1.E. ción de ) (1977). Sobre la apreciación de Ocampo por Lawrence, ver admiración inconmensurable" (2009). 9 Entre otras fuentes, Sebreli toma como referencia reiterada el prólogo de Sartre al libro de Roger Stéphane.

10 Una dedicatoria francamente controvertida. Piénsese en el rechazo y las burlas hacia las feministas y sufragistas en $L a$ razón de mi vida de Eva Perón. 
11 Se refiere a la novela En la semana trágica, publicada en 1965 por la editorial Jorge Álvarez. dos resentidos. [...] La revolución inconclusa comienza con el resentimiento". (Viñas, 1965: 28).

Como se sabe, Sebreli le ganó de mano y publicó su libro en la editorial Siglo Veinte antes que Viñas. Su texto, pionero en su enfoque sobre Evita, parecía responder más a una lógica de provocación y divulgación que a un estudio profundo y exhaustivo-la pregunta del título anticipaba esa dirección-. Esa jugada le valió una discusión en la calle con Viñas, episodio que tiene su costado hilarante. En 1966 Confirmado publicaba el siguiente suelto:

Un año atrás trascendió en Buenos Aires que el novelista David Viñas preparaba un ensayo sobre Eva Perón, para el que recogía minuciosa información. Notas y reportajes en el semanario Marcha de Montevideo y en Confirmado anticiparon incluso el enfoque que Viñas pensaba dar a su estudio.

Sin embargo, su publicación se demoró más de lo previsto y la editorial Siglo Veinte de Buenos Aires consiguió lanzar antes otro ensayo sobre el mismo tema, escrito por Juan José Sebreli: Eva Perón, caventurera o militante? Entretanto Viñas había postergado su trabajo para concluir una novela sobre la semana trágica que acaba de editar Jorge Álvarez. ${ }^{11}$

Cuando el libro de Sebreli se publicó, un periodista lo entrevistó. A lo largo del diálogo Sebreli afirmó que Viñas pensaba llamar Eva Perón, p... o mártir a su trabajo. Indignado, Viñas lo desmintió, pero Sebreli no se retractó. Esa polémica menor se desarrolló sosegadamente hasta pocas noches atrás cuando, un sábado después de medianoche, los dos escritores se encontraron casualmente en la avenida Santa Fe. Sebreli ofreció esta versión del encuentro:

Yo iba caminando por la calle y oigo una voz que me llama: Che, Evita. Me di vuelta, sorprendido; era David, que venía en un coche inmenso, con una pareja de engominados. Se bajó y empezamos a discutir. Al principio él me decía cosas irónicas, pero se fue enojando hasta que me gritó:

-Sos un rufián literario.

-¿Por qué? - pregunté yo.

-En tu libro hacés citas de Hegel.

$-¿$ ¿Y eso qué tiene?

-Y lo vendés en los quioscos, para demostrarle a la gente que no entiende a Hegel.

Este diálogo casi surrealista fue rematado -siempre según Sebreli- por una frase de Viñas que su interlocutor no se animó a calificar de irónica:

-Ahora me voy a MauMau.

(Sebreli, 1966: 6) $)^{12}$

Las dos entregas que Viñas dio a conocer en el semanario uruguayo Marcha en 1965 es lo único que se conoce sobre ese libro que nunca terminó. Las propuestas de estos textos, si bien de forma dispersa, indagan de manera más profunda y sofisticada que Sebreli sobre la trayectoria sociopolítica de Eva Perón, sobre sus lazos con la cultura de su tiempo y sobre el significado de su mito para las perspectivas de la década de 
1960. Viñas coincide, sin embargo, con Sebreli en destacar el "resentimiento" y su "humillación" -y de ahí el vínculo entre Eva Duarte y Roberto Arlt- como fuente de la rebeldía. Esa insubordinación restringida era un punto inicial para la revolución. Escribe Viñas: Nada tiene de raro, pues, que lo más positivo del peronismo sea su negatividad: el haber dicho 'no' a muchos valores de la oligarquía; a ciertas pautas tradicionales. Pero sin superarlos ni proponer otros. De ahí que el peronismo resulte hoy una revolución inconclusa y Eva Perón su símbolo más visible. (p. 24) En esta cita, Viñas se acerca a la idea del peronismo como propedéutica. Lo que no significaba, de ninguna manera, adoptar el evitismo como bandera de la izquierda, sino considerar su fermento de una revolución futura. ${ }^{13}$

El interés de David Viñas, mucho más que el del autor de Eva Perón, caventurera o militante?, es la muestra de la dimensión que Evita tuvo entre los escritores de izquierda durante las décadas de 1960 y 1970 en Argentina. No casualmente, en la última edición de Literatura argentina y política (2005), Viñas cuenta que tenía largas charlas sobre ella en el Tigre con Rodolfo Walsh (autor de ese cuento emblemático sobre el cuerpo de Evita que es "Esa mujer") y sobre su relación parental con Ernesto "Che" Guevara. Aquella mujer pintada por el borgismo como artefacto de una ilusión colectiva, se transformaba en diálogo entre ambos escritores en la madre de la revolución en América. Evita y el Che, puestos en relieve sobre las reticencias hacia los autoritarismos y burocracias de Perón y de Fidel, era la genealogía dilecta que incentivaba el camino de la izquierda. "Walsh se rió con acidez" -escribe Viñas- "y se largó a imaginar una pareja de Eva y el Che. Aunque al final -ya iba amaneciendo y alguien nos llamaba desde el río- sugirió que ese presunto casal hubiera resultado un asunto incestuoso". (Viñas, 2005: 254).

3- En sus escritos, Victoria Ocampo solo se refirió de manera poco frecuente y esquiva hacia Eva Perón. Se dice que en privado la llamaba con el mote sarcástico de "la peronnelle" (juego de palabras que articula el nombre del líder del peronismo con el vocablo francés que remite a una muchacha ingenua, tonta y habladora) y que realizó algunas referencias irónicas en escritos y discursos. Pero no hay ensayos, cartas o relatos en los que Victoria haya volcado una opinión formada y medianamente extensa sobre la primera dama. Sebreli (2011) señala que la directora de Sur respetaba la circunstancia de "hija natural" de Evita (causa de su "resentimiento"), sobre la cual Victoria era especialmente sensible (aunque nada comenta al respecto en Eva Perón ¿aventurera o militante?). ${ }^{14}$ En ocasión de la muerte de Evita y frente a la obligación oficial de publicar la señal de luto, el número 213-214 (julio- agosto de 1952) de Sur salió a la calle con dos pequeños trapezoides negros, ubicados de forma simétrica uno en el borde superior izquierdo, otro en el inferior derecho, como una forma de marcar una distinción frente al resto de las publicaciones que llevaban impresa una franja negra. Ninguna nota alusiva sobre el deceso, ningún obituario, ninguna explicación referente a Evita contenía el número.

Este modo renuente es, sin embargo, congruente con las numerosas veces que Victoria se refirió al "régimen". Pueden recordarse algunos episodios de censura que la escritora delata en sus cartas y en su autobiografía por parte del gobierno hacia sus actividades culturales, como la negativa por parte de la policía de un certificado de buena conducta, documento necesario para obtener el pasaporte, lo que le impidió a Victoria Ocampo viajar en 1953 a recitar la obra Persephone de Igor Stravinsky en Italia y en Estados Unidos. ${ }^{15}$ Pero nunca dedicó un análisis expreso de aquel gobierno ni de sus líderes. Hay, en este sentido, un rodeo sobre un movimiento político al que evidentemente se oponía, actitud bien diferente de otros escritores vinculados a Sur como Borges y Martínez Estrada. Victoria Ocampo prefiere circundar al peronismo: hablar de terribles efectos e impugnables alcances. Victoria tiene un acercamiento pudibundo del mundo político y cultural que emerge con este movimiento. La alusión,
13 Luego de que Viñas publicara sus " 14 hipótesis de trabajo en torno a Eva Perón" en setiembre de 1965 en Marcha, recibió una fuerte crítica por parte de intelectuales comprometidos con el peronismo (Rubén Arbo y Blanco, Pedro Barraza, Daniel Eijel y Osvaldo Lamborghini) en el artículo "Ocho comprobaciones que no exigen mayor trabajo en torno a David Viñas", aparecido en también en el mismo semanario. En setiembre, Viñas les contestó en sus " 14 nuevas hipótesis en torno a Eva Perón":

"Tradicionalmente la izquierda argentina incurrió en un sectarismo que la alejó de los movimientos populares. Por un movimiento pendular -atiborrado de un sentimiento de culpa y de avidez por lograr una identidad sin fisuras-algunos que conocieron por ósmosis ciertos temas de la izquierda se han desplazado al otro extremo: al oportunismo, al seguidismo respecto del peronismo y de lo que Eva Perón encarna como símbolo. [...] Desde este sitial-que a lo sumo representa lo más lamentable de la herencia burocrática- alardean un ademán maniqueo, se otorgan el monopolio del conocimiento del pais y excluyen a quienes no entran en sus esquemas. Simétricos del gorilismo, jamás entenderán un pensamiento problemático. Potenciales burócratas, feligreses del maniqueísmo." (Viñas, 1965: 20).

14 Blas Matamoro, en su libro Genio y figura de Victoria Ocampo (1986), señala que la escritora, aun cuando había sido encerrada, celebró la ley peronista que otorgaba algunos derechos a los hijos "ilegítimos" dictada en 1954: "Victoria Ocampo aplaude la ley que equipara los hijos matrimoniales a los extramatrimoniales, cuando acaba de salir de la cárcel" (Matamoro, 1986:. 279). Respecto de esta norma y de los debates que abrieron entonces, ver el estudio de Isabella Cosse, Estigmas de nacimiento (2005). Por otro lado, Sebreli recuerda una burla de Ocampo destinada a Eva Perón: En ocasión de recibir un premio, Victoria dijo que no iba a declarar, como es de rigor, no ser digna de ese honor, porque la humildad, cuando se ostenta, se destruye: es una virtud innominable, solo puede practicarse en silencio y desaparece a la menor mención. El público festejó con una sonrisa la alusión a la costumbre de Evita, por entonces (1951) en su apogeo, de exhibirse espectacularmente como 'la más humilde de las mujeres'. (Sebreli, 2011: 7) de las mujeres'. (Sebreli, 2011: 7 ) una carta que Victoria Ocampo le envió a Ezequiel Martínez Estrada en 1954 ( $\sin$ fecha exacta). $\mathrm{Ha}$ sido recientemente compilada en el volumen Epistolario (2013). 
16 Todas ellas, por supuesto, contrarias al peronismo. Pero el modo de percibir el significado de los nueve años de gobierno tenía sus matices, por ejemplo, en los textos de Ernesto Sábato, Jorge L. Borges, Tulio Halperín Donghi o Carlos Peralta entre otros. El punto sensible que rompe cierta homogeneidad antiperonista hasta entonces era la adhesión firme de las masas trabajadoras antes $y$ después de 1955 hacia Perón. Sobre las diferencias en el número 237 de Sur ver el recorrido de María Celia Vázquez en "Sur: peronismo y después" (2011). Sobre las fisuras que después" (2011). Sobre las fisuras que
comienzan a ponerse de manifiesto en el cenáculo de Victoria Ocampo, ver el texto de Jorge Cernadas "Notas sobre la desintegración del consenso antiperonista en el campo intelectual:

Sur, 1955-1960" (1997). Beatriz Sarlo, asimismo, en La batalla de las ideas (2007) realizó un profundo y rico estudio sobre los debates que se suscitaron en todo el arco intelectual el problema sociopolítico que implicaba la experiencia del peronismo y su presencia en la sociedad luego de que su líder fuera derrocado. Respecto de sus importan upturas en el campo de la cultura, ver el estudio de Oscar Terán Nuestros años sesentas (1991). 17 Este "pudor" de la escritura de Victoria Ocampo es el que Oscar Masotta fustigó en Contorno en el artículo “'Sur' o el antiperonismo colonialista" (1956). 18 Aun así en el libro se refiere a Eva Perón y a ella misma solo por las iniciales: E o E.P. y V.O.

19 Subrayado en el manuscrito. la metáfora, la ironía, el rodeo, el pie de página son las modalidades públicas por las que Victoria habla sobre el peronismo. En uno de sus tomos autobiográficos, por ejemplo, refiriéndose al escritor (y amante) Pierre Drieu La Rochelle anota: "Pero jes que no estamos todos más o menos arrojados a un callejón sin salida? ¿No lo estamos nosotros aquí?" De inmediato, en un llamado al pie de página, explica: "Escribo esto en la primera presidencia de Perón" (Ocampo, 1983: 78). Victoria Ocampo necesita, como se ve, un sistema de referencias disimuladas y un pie de página para referirse al gobierno peronista.

En el célebre número 237 de Sur, de noviembre de 1955, en el que diferentes figuras intelectuales sentaron sus visiones sobre el peronismo, ${ }^{16}$ Victoria se despachó con mayor vehemencia sobre el gobierno caído, en particular en sus dos artículos "La hora de la verdad" y "El hombre del látigo". En ellos, además de contar sus penosas experiencias en la cárcel, trazaba la continuidad entre el nazismo y "la dictadura". En ninguno de los dos aparece la palabra "Perón" ni "Eva". Victoria no parece poder escribir estos términos. Incluso con el título "El hombre del látigo" alusivo a la famosa biografía de Mary Main sobre Eva Perón (La mujer del látigo), desplaza el supuesto foco pernicioso desde Eva hacia Perón o hacia el movimiento al que caracteriza en la imagen de un sádico golpeando a su propio caballo indefenso. ${ }^{17}$

Lo destacable del libro de Sebreli anotado es que, por primera vez, un lector descubre a Victoria escribiendo francamente sobre la mujer de Perón, encuentra sus trazos nerviosos sobre un objeto que la excita, se halla frente a la postura desembozada sobre un objeto tan presente como renuente de su producción: Eva Perón. ${ }^{18}$ Las anotaciones y los subrayados no buscan argumentar con suficiencia, no quieren ser elegantes ni sofisticados, ni siquiera ingeniosos. Se trata sencillamente de comentarios crispados y de contestaciones (porque ante todo, se trata de esto) que surgen de la bronca sobre esa figura a la que Sebreli se atrevió a equipararla. Por ejemplo, cuando Sebreli cita un fragmento de La razón de mi vida en la página 39, en el que Evita dice que va a entregarse a un "incomprensible sacrificio", Victoria subraya el texto entrecomillado, repite signos de interrogación, y anota: "Por qué comprensible? Por qué sacrificio? Busca venganza?". En el pasaje de la página 32 el que el ensayo compara a Victoria con Eva, asegurando que la primera fue la "enemiga acérrima" de la primera dama, la escritora, subraya con frenesí, repite signos de exclamación e interrogación, traza líneas verticales y agrega: "¿Y el peronismo no fue enemigo acérrimo de V.O.?". Otro ejemplo: en una nota al pie de la página 96, Sebreli asegura que Victoria ha otorgado "desorbitadas donaciones" pero no a los pobres argentinos sino a intelectuales Europeos. Frente a esto, Ocampo escribe debajo: "He dado incomparablemente más aquí que en Francia". ${ }^{19}$

Todo ello lleva a pensar que los subrayados y anotaciones en el ejemplar de Eva Perón, ¿aventurera o militante? expresan claramente que la mirada de Ocampo va a contramano de aquellas relecturas sobre Eva Perón que se estaban elaborando desde la nueva izquierda. Esto es: si Evita se transforma en el puntal de una revolución inacabada, si el peronismo era propedéutica de una trasformación sociopolítica, Victoria contesta (escribe) irritada que Eva fue arribista y frívola, que nunca dejó de usar ropa de alta costura, que no fue una figura emancipadora de oprimidos ni de minorías. En otras palabras, Victoria Ocampo insiste con el ideario de Evita como figura de simulacro, línea que había dominado la lectura del peronismo hacia 1955 y que ella misma había abonado cuando le agradecía a Dios que en la cárcel hubiese conocido por fin la "realidad" (Ocampo, 1955: 5). Sebreli escribe que Evita "en un periodo de su vida" fue solo una mujer que "ostentaba" su variado y rico guardarropa. Victoria anota en el margen: "Toda su vida". Sebreli intenta "separar" (no del todo, claro) a Evita de los "vicios" de Perón; Victoria "reperoniza" a Evita, la vuelve a ligar a la "dictadura". Tira por tierra toda idea de liberación de las mujeres que hubiese producido o fomentado 
Eva, incluso la posibilidad de votar, que para Victoria no era un logro pues provenía de un gobierno "de facto". ${ }^{20}$ Frente al desprecio de La razón de mi vida por las sufragistas y feministas (a las que trata literalmente de feas y solteronas), Victoria anota molesta: "(repugnante)". En el margen agrega: "esto prueba la incapacidad de E. para entender este aspecto social y el tremendo problema”. (1966: 61).

4- No es un mero detalle que estos trazos francos e irritados sobre Evita hayan sido hechos a mano y sobrescribiendo otro texto. Victoria contesta a la construcción que realiza Sebreli a través de llamadas en los márgenes del texto, destacados, tachados y subrayados. Antes que interpretar o pronunciarse sobre Eva Perón, escribe con sus manos -gestualiza-. "La relación con la escritura es la relación con el cuerpo" afirma Roland Barthes (2003, p. 122) refiriéndose a ese vínculo que hace que el cuerpo se estremezca y se movilice sobre una hoja de papel. Las manos -y por ende el cuerpo-se agitan en la lectura y la escritura. Los comentarios de Victoria sobre la Eva de Sebreli la muestran, así, muy lejos de cualquier imagen de continuidad o de aplomo intelectual. En su escritura, Victoria pierde la mesura.

Esta imagen muestra a Victoria escribiendo en secreto, en la soledad de su escritorio, expresando todo aquello que no decía en público. La directora de Sur no dicta, anota personalmente, como lo haría en un diario personal. La escritura sería, en este sentido, el recipiente de lo oculto (de aquello no dicho, de aquella postura impúdica), y en cierto modo, la guardiana de lo vedado. Pero, siguiendo a Barthes, para nada la "expresión de su personalidad": las caligrafías y notas de V.O. son tan diferentes entre página y página que si el ejemplar hubiese sido encontrado en otra biblioteca, podría pensarse que fue anotado por más de una persona o que tal persona lo realizó en momentos distintos de su vida - ¿y acaso no pudo ser así? Imaginemos a Victoria revisitando el libro periódicamente-. No hay testimonios de alguien que la haya visto anotar el libro, no hay firma, la dedicatoria se encuentra en otro ejemplar. ¿Qué es lo que permite pensar que tales frases fueron realizadas por Victoria? En primer lugar, un trazo similar de un lápiz rojo (cuyo contraste con la letra impresa trae consigo la imagen de la corrección de un texto). O sea, la materialidad de un gesto continuo. Luego, su pertenencia a un archivo y a una institución (la Fundación Victoria Ocampo) que retiene a la vez que difunde la obra de Victoria Ocampo.

¿Cuál fue la razón por la que Victoria escribiera sobre un ejemplar distinto al que le regalaron? Es evidente que ella realmente tenía un interés vivo sobre el libro y que quería anotarlo. Quería además que su letra, por más diferencias que tuviese, fuese leída. No se deshizo de ninguno de los dos libros (como hubiese sido en el caso de un secreto inconfesable que la hubiese llevado a la destrucción del libro), sino que conservó ambos en su archivo para futuros lectores -procedimiento semejante al de sus tomos autobiográficos, mandados a imprimir luego de su muerte-. En palabras de Jacques Derrida (1997), el archivo es un aval de porvenir. La escritura en este caso, desviada de la autoría, se transforma en un espacio que respira sin el peso de la subjetividad. El hecho de que Victoria, frente a su propia finitud, guardara -archivara- los ejemplares de Eva Perón, ¿aventurera o militante? puede entenderse también como la apertura de la posibilidad de leer unos trazos descentrados y sin pudor, fuera de la obra, una escritura discontinua e irritada, al margen y destacando(tachando, subrayando, complementando) otro texto.

Lo singular de este procedimiento es que tiene como objeto a Eva Perón, aquella que era presentada como contrafigura de Victoria Ocampo. Esta optó por no opinar abiertamente sobre esa otra mujer que la irritaba y a la que ciertamente no respetaba. La figura de Evita le provocaba mucho más que lo que podría haber dicho con serenidad en un debate o en una conferencia. Sobrescribió, entonces, en la soledad de su oficina, anotó al margen de otro texto, tachó una lectura de Eva que iba a contramano de su
20 Sebreli (1965) señala que tal aseveración fue realizada por Victoria en una conferencia que ella realizó en 1945 . 
21 Victoria se refiere a Alberto Dodero, poderoso empresario naviero, cercano del matrimonio Perón y del gobierno peronista.

22 Con variada documentación, Beatriz Sarlo en el ensayo La pasión y la excepción (2003) explica en detalle la vestimenta y peinados de Evita desde su época de actriz hasta su llegada al poder. También en el libro Comediantes y mártires (2008) de Sebreli pueden encontrarse datos sobre la construcción de la "imagen" de Eva, pero plan de desmitificación que se contrapone ne evidentemente lo que había planteado en 1966.

23 Nótese que ni Victoria ni Sebreli advierten la dimensión simbólica de la vestimenta de esta mujer del poder.

En La pasión y la excepción (2003).

En La pasióny la excepción (200

Beatriz Sarlo explica el carácter de

"excepcionalidad" de la figura de

Evita en el campo político. Esto es,

lo que en el ámbito del espectáculo

(específicamente del star system loca

de los cuarenta) resultaba insuficien-

te, en el poder se dimensionaba y

te, en el poder se dimensionaba

se tornaba particularmente valioso.

de Eva es un desplazamiento. Su excepcionalidad es un efecto del

'fuera de lugar', que no quiere decir

lo obvio (que llegaba de afuera de la clase, del sistema), sino que sus cualidades, insuficientes en unaescena (la artística), se volvían excepcionales en otra escena (la política)." (Sarlo, 2003: 24). Por otro lado Sarlo subraya la característica de "doble cuerpo" (concepto que toma de Ernst Kantorowicz) que encarna quien detenta el poder, en tanto ese cuerpo representa y proyecta al mismo Estado. La ensayista ha vuelto sobre este planteo en el artículo "Fuera de campo o la intimidad de Eva" (2012) en el que estudia fotografías de Evita realizadas por Giselle Freund. opinión y, sobre todo, una equiparación que no toleraba. Luego, en silencio, guardó cuidadosamente el ejemplar en su biblioteca.

5- Cada vez que Juan José Sebreli destaca rasgos de sencillez o humildad de Eva, Victoria Ocampo lo contradice con el mismo argumento: nada había de modesto en esa mujer poderosa y vestida ostentosamente. El texto destaca que en la época de "señora", la primera dama usó vestidos y joyas lujosos. Victoria escribe a un costado "Todo el resto de su vida" (p. 60). Sebreli se pregunta si la imagen de una mujer "rebelde" (p.33) de la alta burguesía como Victoria Ocampo podía incentivar a identificarse con ella a la obrera o a la sirvienta (en comparación tácita con Evita). Ocampo interroga irónicamente en el margen: "Cuando EP se vestía en Dior se podían identificar con ella la obrera, etc." (p. 33). Otros ejemplos de Eva Perón, ¿Aventurera o militante? parecen tener el mismo sentido. Victoria no aceptaba ninguna formulación sobre la imagen de sencillez de Evita. Ella era parte de una escenificación, pero no a la manera de un maniquí (Borges) o de un robot (Ghioldi), sino como una mujer ambiciosa y oportunista. Esta es la imagen que parece trazarse cuando anota: "Su ropa pagada por Dodero, la historia de sus pieles, etc." (p. 52), ${ }^{21}$ "Fuera del dinero que sacaba de cualquier bolsillo" (p. 102). La palabra "Dior" que se repite en sus comentarios condensa ese apetito desmedido por objetos suntuarios por parte de Eva. El énfasis sobre Dior, en tanto moda asociada a la extravagancia y al derroche, así como a cierta construcción consecuente de la mujer como objeto, quería desbaratar la construcción de la imagen "militante" de Evita en los sesenta.

El viaje de Evita a Europa en 1947 se realizó, justamente, con el lanzamiento del new look de Dior. Mientras estuvo en el poder, Evita compró (o mandó a pedir) frecuentemente en las casas de alta costura de París: Dior, Balenciaga, Fath, Reboux y otras. Una corte de peinadores, asesores, maquilladores y modistos rodeó a Eva desde 1945. El guardarropa de Eva desbordaba de zapatos, pieles, vestidos y joyas. ${ }^{22}$ Glamour y brillo, ostentación y centelleo para esta joven y bella mujer que se consolidaba en el poder. Fue así como iría forjando su imagen palatina, una suerte de reina del país peronista. Eva Perón, ¿Aventurera o militante? advierte, sin embargo, un giro que se habría producido en los últimos años de la vida de Eva. Las "bananas" y los peinados rebuscados cambiaron por el sencillo rodete; los vestidos suntuosos se esfumaron y en su lugar apareció el traje sastre (el tailleur príncipe de Gales, creado por el modisto Paco Jamandreu), mitificado en la última versión viva de Evita. Era la forma en que la apariencia hablaba de la dialéctica entre "aventura" y "militancia". ${ }^{23}$

Por el contrario, Sebreli presenta la vestimenta de Victoria Ocampo como el aditamento consecuente de la oligarquía y la contracara opuesta de la primera dama del peronismo. "Lleva desde hace años" escribe en Buenos Aires, vida cotidiana y alienación (1964). Y sostiene: un sencillo "dos piezas" de color azul con el saco puesto sobre los hombros a la 'sansfa on' aparentando haberse vestido de prisa, como al descuido. La burguesía antigua huye de la elegancia demasiado estridente, chillona, se siente segura de sí misma y no necesita llamar la atención como la clase media." (Sebreli, 1964: 55). En Los oligarcas (1971) insiste en la misma línea de comprender la vestimenta del patriciado: "Sigue moda francesa o inglesa más tradicional. Detesta la ropa nueva, 'endomingada', y hasta es capaz de usar permanentemente la misma indumentaria como una forma de originalidad". (Sebreli, 1971: 82). La moda explicaría la clase: llevar el mismo conjunto simple significa estar por encima de los excesos de una clase media que busca obtener capital simbólico. Solamente el detalle del "saco sobre los hombros" pinta en Victoria cierta soltura, cierta autoridad autosuficiente, cierto aire de potestad. Una línea sencilla era la marca exacta de una mujer que no necesita presumir su pertenencia de clase. 
Aparentemente, el comentario burlón sobre su vestimenta no pasó inadvertido para Ocampo. Sebreli refiere con humor en su autobiografía (2005) que desde entonces alternó su típico traje azul con uno idéntico de color marrón. No obstante estas chicanas, Victoria estaba de acuerdo con subrayar, dando vuelta el argumento de Sebreli, la sencillez en su vestir, acaso como forma de dar cuenta de la ausencia de dobleces y de su transparencia ética. En 1968, contestando una nota de la revista Atlántida en la que se referían a su coquetería, Victoria escribió al director de esta publicación: Se habla por ahí, en su revista, de mi coquetería. No me parece mal ser coqueta. La señorita de Atlántida anotó que yo tenía el pelo blanco. Deploro tenerlo aún castaño en la nuca. Lo que debió anotar su corresponsal son las siguientes datos: 'No se tiñe; no se bate el pelo; no se pinta las uñas; no usa pestañas postizas ni rimmel; no ha adoptado la minifalda; anda de alpargatas (aunque no prefiere la alpargata al libro); no ha recurrido a la cirugía estética; parece limpia; usa polvos ocre y rouge (el rouge ya no se usa); está quemada por el sol.' A esto se reduce la lista de mis coqueterías. (Ocampo, 1968: 141). Con esta construcción, se diría que se trata de una señora en extremo modesta y hasta rústica (de acuerdo con el detalle del sol y del calzado), más allá de su fortuna y de su clase.

Esa imagen contrasta con aquella mujer que durante las décadas de 1920 y 1930 era asidua compradora de los sombreros de Reboux y de las prendas de Chanel. Victoria adoraba los diseños de esta última casa parisina. En sus Testimonios, Ocampo escribió sobre sus visitas a la tienda de la rue Cambon y de la amistad que forjó con Coco Chanel. La crónica da cuenta de cierta experiencia estética en el momento en que se probó un pulóver Chanel. La vendedora le dijo que le asentaba muy bien la combinación "chiné". Victoria nunca había oído esa palabra, que se refería a la mistura entre un fondo castaño en los que sobresalían figuras en celeste y rosa. "Chiné" era algo más: se trataba de un concepto de buen gusto. Victoria ornamentó su departamento de la avenue Malakoff bajo este gusto, que combinaba la rusticidad (mesa de pino blanco, sillas de paja, sillones de mimbre) con detalles de lujo (cubiertos de plata, cepillos de carey con detalles en oro). "Esta mezcla" -anota Victoria- "este chiné tenía cierto parentesco con el tailleur de satin y el sweater de changador de Chanel. Podía parecer afectación. No lo era. Era un signo de los tiempos. Tiempos de transición aguda". (Ocampo, 1975: 124).

Chanel no solo era una modista en boga durante la década de 1920 . Su ropa desprendía una modernidad y ciertos rasgos de acceso social propios de la sociedad en la que emergía. Las líneas sencillas, rectas y clásicas de sweaters y trajes sastres huían de los rebusques (algo que desagradaba particularmente a Ocampo). Servían para la mañana y para la noche, podían usarse una y otra vez sin parecer repetitivos. Una primera apariencia de esta ropa hacía lucir un poco simple a quien la vestía, pero los detalles y la alta calidad los volvían especialmente elegantes. Las joyas de Chanel, no querían ser objetos preciosos, eran, en cambio, accesibles y sentadores para cualquier mujer (aunque no para todas), y de este modo "Chanel ponía así punto final a ciertos privilegios". (Ocampo, 1975:122)

Este era el atractivo de Chanel: modernidad, distinción, mesura. Aspectos que eran edificantes del gusto social y cultural de Victoria. La suya era menos, entonces, tosquedad o sobriedad de una clase patricia y agrícola que el derrotero tardío de una visión estética modernizadora de la década de 1920. Es natural suponer el rechazo de la sobrecarga de vestidos y joyas de Evita, tanto si se la vincula a la apariencia "cargada" de las clases en ascenso o si se mira a través del new look de Dior-no es casual que haya sido cuestionado por mostrar a la mujer como un objeto lujoso y caprichoso-. Chanel, en esta perspectiva y teniendo en cuenta las distancias temporales, se contraponía a Dior: la discreción, la sobriedad y sobre todo la medida discrepaban con el artificio, la exuberancia y el exceso. 
24 Sobre estas versiones de sacralización ver la compilación de Marysa Navarro, Evita. Mitos y representaciones (2002).
25 El concepto de desprecio remite al análisis de Peter Sloterdijk en su ensayo El desprecio de las masas (2002). En este texto, el pensador alemán advierte una tensión constitutiva entre la cultura que surge de las masas y la que permanece en las elites. Hay asi que permanece en las elites. Hay as moderna por la masiva, pero también hay desprecio entre algunos sectores de la cultura hacia el esnobismo antipopular. Dice Sloterdijk: “la compleja estructura del desprecio moderno en cuanto tal, que siempre entra en escena como desprecio que desprecia y como desprecio despreciado, realiza complicadas y peligrosas aproximaciones a un campo contaminado en el que predominan el narcisismo inseguro de las masas y las ambiciones heridas de las elites, cuando no sus mutuos entrecruzamientos." (Sloterdijk, 2002: 64).
6- ¿Por qué escribir al margen, por qué subrayar frases sobre un libro impreso? Se dirá, de forma preliminar, que quien apunta al margen, que quien traza líneas, imprime una lectura individual. Los libros se anotarían para dejar asentada una interpretación, o quizá menos, para iluminar fragmentos que guardan determinado interés para el lector. La nota y el destacado darían cuenta, así, de un modo personal de apropiarse del texto. De acuerdo a ello, se trataría de una herramienta para particularizar y diferenciar un material que está destinado, mediante la reproducción de la imprenta, a cientos o a miles. Esta primera respuesta estaría suponiendo, asimismo, un lector que interviene sobre la multiplicidad y construye su singularidad a partir de su intelecto (se distingue del molde, se distancia de la igualación). El acto de anotar se presume como un artificio de un logos preeminente; un artefacto de la palabra para "marcar" aquello que el raciocinio edifica en un sujeto relativamente centrado y coherente. ¿Pero qué sucede cuando la sobrescritura no nace de aplomo de la razón, sino de la contrariedad o de la rabia? No puede haber marcas ni destacados edificantes. Lo que puede encontrarse, de lo contrario, son respuestas de diferenciación negativa arrancadas por una frase que excita el enojo. Nada de "apropiación" para Victoria Ocampo: no hay que iluminar nada del texto de Sebreli (un texto que menosprecia). Ocampo no "ilumina"; contesta diatribas o corrige (no se puede obviar el detalle del lápiz rojo) los pasajes o las frases con los que disiente.

Se dirá también que se anota como un paso preliminar a la escritura de otro texto. Esto es, se anotaría para tomar ideas o frases, para parafrasear teorías, para contestar determinadas opiniones, para extraer un ejemplo oportuno, etc. Se anotaría y se subrayaría para escribir, se sobrescribiría para producir. Victoria Ocampo, no obstante, no planea escribir nada. Su lectura y sus notas son completamente improductivas. El ensayo no le sugirió una visión novedosa de Evita ni pareció reafirmar en ella sus reparos previos. Victoria anota en plan de improductividad. No quiere forjar obra y ni siquiera escribir algo sobre ese objeto que la irrita, Evita. Por eso no escribe: sobrescribe.

Habría que considerar, en cambio, dos hipótesis sobre la actitud de Victoria Ocampo respecto del libro de Sebreli. En primer lugar, la directora de Sur sobrescribe como forma de negar la sacralización de Eva Perón. Esto es, de cara a la elevación monumental de Evita, del crecimiento del mito de su cuerpo escondido, del respeto sagrado y popular hacia su imagen y de la emergencia de su figura reconvertida en vanguardia para el peronismo de izquierda en los sesenta, ${ }^{24}$ Victoria reniega de un culto. Ocampo anota y subraya como si garabateara un monumento honorífico o como si realizara un gesto de blasfemia durante una liturgia. Su desprolijidad manuscrita, la caligrafía cambiante y desordenada, su ademán arrebatado y, sobre todo, el modo furtivo de su escritura la muestran como una especie de enérgica renegada de la hagiografía de Eva. Todo ello, siempre y cuando se tenga en cuenta el detalle de que el acto de Victoria es reservado, es decir, contrario a toda demostración pública de su irreverencia.

La segunda hipótesis sobre la sobrescritura de Victoria es que se trata de una forma pudorosa y alambicada de desprecio. ${ }^{25}$ La mano que tacha y objeta está recorrida por un conflicto cultural. Victoria, la propulsora de una cultura cosmopolita y moderna en Argentina (cf. Aguilar, 2009), no puede sino repulsar todo el espectro masivo y popular que encarnaba Eva Duarte (desde su labor en el cine y en la radio a la conducción de las masas peronistas). No obstante, de acuerdo a su credo humanista e igualitario, asociado a los caracteres de democracia liberal, la escritora no podía rechazar de plano todo eso que significaba la figura de Evita-muestra de ello era la consideración de la circunstancia de hija "natural"-. Su feminismo era un obstáculo además para impugnar directamente a otra mujer que había sufrido el escarnio social (y hasta el mancillamiento de su cadáver) por su condición de mujer. Su desprecio público sería una contradicción difícil de sostener. Victoria entonces no se pronuncia abiertamente Evita. Anota sobre el texto de otro que la encomia para mostrar, discretamente, la 
diferencia insalvable que hay entre ella y esa otra mujer. El ejemplar anotado de Eva Perón, ¿aventurera o militante? habla entonces de una incisión (secreta, sí, pero evidentemente clara), de las contradicciones, los límites y las aporías entre elites modernas y agentes de la cultura de las masas en el marco de la presencia del peronismo. Desde este punto de vista, Victoria elige no leer ni escribir expresamente sobre Eva (o sobre sus discursos, o sobre La razón de mi vida) sino sobre un ensayo que estaba llevando al objeto Evita desde la esfera de la cultura popular y masiva hacia el campo intelectual de los sesenta. La intervención de Ocampo está inscripta en este desplazamiento. ${ }^{26}$

7- En el ensayo Comediantes y mártires (2008) Juan José Sebreli volvió a la figura de Evita (y ya no a "Eva Perón", que a esta altura resulta muy fría respecto del mito popular) y al libro que él había escrito en la década de 1960. En el prólogo advierte que la lectura que había hecho entonces había sido errada: "El libro sobre Evita de 1966 no estaba logrado porque equivoqué de género. Me dejé llevar por el prejuicio de esa época que consideraba a la biografía un subgénero menor y pasado de moda. Por añadidura, el tema de Eva Perón no tenía en esos años nivel académico; era solo objeto de una literatura panfletaria. Intenté escribir un ensayo político cuando lo adecuado era una biografía, porque Evita antes que una política era un mito. (Sebreli, 2008: V) Este Sebreli ya no es el joven entusiasmado con las ideas del existencialismo e ilusionado con las posibilidades de una revolución. Tampoco, claro está, con algún dejo "propedéutico" de rebeldía que pudiera tener el peronismo, aspecto que argumentó extensamente en el ensayo Los deseos imaginarios del peronismo en 1983, en el que remarcaba y abjuraba los caracteres "bonapartistas" y autoritarios del movimiento.

Lo interesante de esta nueva lectura que realiza Sebreli es que coincide en gran parte con la que tenía Victoria Ocampo. En su nuevo ensayo señala, por ejemplo, que la actuación es la forma más adecuada de entender la construcción de su figura pública, cuando interpretó el papel de su vida, argumento que trae consigo la imagen de Evita como artificio. En Eva Perón, ¿Aventurera o militante? Victoria había subrayado alarmada la frase de Sebreli: "ella, que no lograra ser sino una discreta actriz, alcanzará momentos sublimes cuando hable a las masas trabajadoras" (Sebreli, 1966: 45). En Comediantes y mártires el ensayista destaca la afirmación patriarcal y sexista de Eva (y del peronismo por extensión), en contra de cualquier lectura de género y queer (Sebreli nombra a Copi y a Perlongher), y la describe como una muchacha asexuada y fría, imagen que contrasta con la revuelta "clitoriana" que parecía asomar con ella en los sesenta. Ambos coinciden también en rechazar los logros para la mujer y en impugnar el antifeminismo de Evita. En el texto de 2008, Sebreli compara las actitudes semejantes que pueden encontrarse entre los autores de Mi lucha y de La razón de mi vida. Frente a la frase que aseguraba que "Eva Perón mostró ser más historia que ellas" (Sebreli, 1966: 117) refiriéndose a las sufragistas, Victoria había escrito en un margen: "Hitler es historia también". Y los puntos de contacto siguen.

En la década de 1960, Sebreli creyó encontrar en Evita la figura en la que convergían las transformaciones políticas, sociales y sexuales, y en Victoria, a una rival de un fragmento residual de la cultura. Esta polaridad imaginada entre esas dos mujeres a las que necesitaba enfrentar es lo que lo empujó a dedicarle un libro a la primera y provocó, directa o indirectamente, que Ocampo escribiera sobre Eva Perón. Medio siglo después y con un giro ideológico mediante, Sebreli quiere desmotar todos los mitos de Evita y reniega haber escrito aquel libro al que considera un pecado de juventud. Una actitud que lo hace confluir finalmente con Victoria Ocampo. Como si las letras rojas y desprolijas de esta se hubiesen superpuesto sobre la letra de molde de Eva Perón, ¿aventurera o militante?

8-Sebreli imaginó una Victoria enfurecida frente a la dedicatoria que la equiparaba con Evita. Una revancha del ensayista que excedía su propio enfrentamiento con la
26 En Comediantes y mártires (2008), Sebreli advierte que en aquella época realizar un estudio sociológico sobre un objeto popular y cruzado por el debate político como era Eva Perón era una verdadera audacia. De hecho es él quien introduce a Evita como un objeto de estudio válido para el campo intelectual. Los ensayos previos sobre Evita solo son ejercicios de desprecio cultural y político. 
27 Me refiero a la lectura de Rodríguez Monegal y de Héctor Murena de las transformaciones del campo cultural argentino bajo la forma de un parricidio. Ver al respecto sus ensayos El juicio de los parricidas (1956) y E pecado original de América (1954). directora de Sur. Se trataba también de un ajuste de cuentas generacional, episodio algo rezagado de la ruptura dentro del campo cultural durante los años cincuenta, que algunos intelectuales, como Héctor A. Murena y Emir Rodríguez Monegal, interpretaron como una tragedia familiar. ${ }^{27}$ Más aún, la imagen de una Victoria doblegada, furibunda, derrotada por Eva acompañaba un imaginario colectivo. Ese imaginario ostentaba la rivalidad entre, por un lado, la figura mítica de una hermosa muchacha humilde que había llegado al poder, había acompañado al movimiento obrero, había muerto joven y su cadáver, deshonrado y mutilado, era todavía una incógnita; por el otro, una señora mayor, reaccionaria, afrancesada, irascible, mundana y aristocrática. Por fuera de la imprecisa veracidad de esas suposiciones, la sonrisa maliciosa de Sebreli captaba un momento cultural y político de transformaciones en el que un corte social y cultural que en otro momento había sido dominante, era desplazado.

Sin embargo, el enfrentamiento imaginario entre ambas da cuenta de la permanencia y la hondura de una pugna. ¿Es necesario que Victoria hable con Eva, de que Eva le responda a Victoria? ¿Por qué habrían de hablar ellas dos que no tenían en común más que el género y la patria-a los que entendían, por cierto, de manera muy diferente-? ¿En qué se fundamenta el apremio de reunirlas una frente a la otra, de establecer un diálogo o una discusión entre estas dos mujeres que provenían de cortes generacionales, sociales, políticos y culturales tan distantes? Hay, como primera respuesta tentativa, una actitud deliberadamente ingenua, una idea que especula con una conciliación estructural en un plano imaginario frente un fracaso histórico persistente. O bien una dosis de crueldad en esta reunión forzada, como encerrar en una misma habitación a dos personas que se detestan. Para poder suponer tal escena hay que pensarse un guardián indolente que observa con placer a dos personas enfrentadas, esperando que choquen. Se trata de dos mujeres colocadas en un mismo espacio frente a los ojos de una multitud deseosa. Dos mujeres, también, cuya condición de género les significó dificultades particulares, que deben hablar entre sí. Nuevamente, ¿Es necesario que ambas hablen? ¿Es posible, por el contrario, que se considere la irreductibilidad de sus perspectivas, de sus condiciones, de su peso histórico? ¿Es posible pensar la inconmensurabilidad comunicativa entre las dos, lo irreductible de sus gustos, la diferencia de sus posturas?

Por eso, tal vez, Victoria no habla, no contesta a las provocaciones. Sobrescribe y archiva. Anota las páginas de su propio libro. . Su forma deliberadamente alambicada de llegar hasta Eva (a través de sus inscripciones en un libro de un tercero guardado en su casa) muestra su estrategia: un mutismo público, contracara de su furia privada, desarma el deseo de verla frente o junto a Evita. 


\section{Q Bibliografía}

»Aguilar, Gonzalo (2009). Episodios cosmopolitas en la cultura argentina, Buenos Aires, Santiago Arcos editor.

" Avellaneda, Andrés (2002). “Evita: cuerpo y cadáver de la literatura” en Evita. Mitos y representaciones, Buenos Aires, Fondo de Cultura Económica.

»Barthes, Roland (2003). Variaciones sobre la escritura, Buenos Aires, Paidós.

" Cernadas, Jorge (1997). "Notas sobre la desintegración del consenso antiperonista en el campo intelectual: Sur, 1955-1960", en Cultura y política en los años '6o, Buenos Aires-Rosario, Instituto de Investigaciones “Gino Germani”Facultad de Ciencias Sociales- Universidad Nacional de Rosario.

»Confirmado (1965, 16 de julio). David Viñas, frente a Eva Perón: ni obsecuencia ni agravios. Confirmado, 11, 16 de julio de 1965, p.28.

»Confirmado (1966, 2 de junio). Viñas- Sebreli. Altercado. Confirmado, 50, 2 de junio de 1966, p. 6.

" Cosse, Isabella (2006). Estigmas de nacimiento. Peronismo y orden familiar 19461955, Buenos Aires, Fondo de Cultura Económica.

»Derrida, Jacques (1997). Mal de archivo. Una impresión freudiana, Madrid, Trotta.

» Ghioldi, Américo (1956). De la tiranía a la democracia social. Cayó la dictadura ¿y ahora qué?, Buenos Aires, Gure.

» Helft, Nicolás (2011). “Victoria y Evita. Venganza, poder y Dior”, adn Cultura (La Nación), núm. 204, julio.

»Huyssen, Andreas (2006). Después de la gran división. Modernismo, cultura de masas, posmodernismo, Buenos Aires, Adriana Hidalgo.

»Masotta, Oscar (1956). “'Sur’ o el antiperonismo colonialista”, Contorno, núm. 7- 8, julio.

"Matamoro, Blas (1986). Genio y figura de Victoria Ocampo, Buenos Aires, Eudeba.

" Murena, Héctor (2006) [1954]. El pecado original de América, Buenos Aires, Fondo de Cultura Económica.

" Ocampo, Victoria (1942). 338171 TE, Buenos Aires, Sur.

"---------- (1951). Lawrence de Arabia y otros ensayos, Madrid, Aguilar.

》--------- (1955). “La hora de la verdad”, Sur, núm. 237, noviembre-diciembre.

"-------- (1955). “El hombre del látigo”, Sur, núm. 237, noviembre-diciembre.

»---------- (1963). “El claustro de T. E. Lawrence”, en Testimonios. Sexta serie (1957- 1962), Buenos Aires, Sur.

" ------ (1967). “Propósitos de Lawrence de Arabia” en Testimonios. Séptima serie, Buenos Aires, Sur.

》---------- (1968). “Aclaraciones”, Sur, núm. 311, marzo-abril.

»-------- (1975). “Sinónimo de París”, en Testimonios. Novena serie (1971- 1974), Buenos Aires, Sur.

”--------- (1977). “Am Sam Dram (El enigma de T. E. Lawrence ”, en Testimonios. Décima serie (1975-1977), Buenos Aires, Sur. 

(1982). Autobiografía IV. Viraje, Buenos Aires, Sur.

$»$ Aires, Sur.

» ---------- (1984). Autobiografía VI. Sur y Cía, Buenos Aires, Sur.

»Ocampo, Victoria y Martínez Estrada, Ezequiel (2013). Epistolario, Buenos Aires, Interzona.

»Perón, Eva (1951). La razón de mi vida, Buenos Aires, Peuser.

»Prior, Aldo (1964, noviembre- diciembre). Juan José Sebreli. ‘Buenos Aires, vida cotidiana y alienación'. Sur, 291, 79- 82.

» Rodríguez Monegal (1956). El juicio de los parricidas, Buenos Aires, Deucalión.

»Sarlo, Beatriz (2003). La pasión y la excepción, Buenos Aires, Siglo XXI.

» ---------- (2007). La batalla de las ideas (1943- 1973), Buenos Aires, Emecé.

»---------- (2012). Fuera de campo o la intimidad de Eva. La Biblioteca, 12, 100123.

"Sartre, Jean-Paul (1965). "Retrato del aventurero (Introducción a Portrait de l'aventurier de Roger Stéphane)", en Problemas del marxismo I. Situations, Buenos Aires, Losada.

» Sebreli, Juan José (1952). “Cinematógrafo. Dos juicios sobre 'Monsieur Verdoux”, Sur, núm. 211- 212, mayo-junio.

»------- (1952). “Cinematógrafo. ‘El destino me condena”, Sur, núm. 213- 214, julio-agosto.

» --------- (1952). “Celeste y colorado”, Sur, núm. 217- 218, noviembre-diciembre.

» -------- (1953). “Inocencia y culpabilidad de Roberto Arlt”, Sur,núm. 223, julio-agosto.

» ----------- (1954). “Alberto Girri. ‘Misántropos’”, Sur, núm. 226, enero-febrero.

»--------- (1954). “Ramón Ferreira. ‘Tiburón y otros cuentos’”, Sur, núm. 227, marzo-abril.

»---------- (1954). “Rodolfo Kusch. ‘La seducción de la barbarie’”, Sur, núm. 228, mayo-junio.

»--------- (1954). “La acción de Sarmiento y la razón de Alberdi”, Sur, núm. 230, setiembre-octubre.

» --------- (1955). “Ernesto Palacio. “Historia de la Argentina 1515- 1938’”, Sur, núm. 234, mayo-junio.

» ---------- (1955). “Miguel Ángel Speroni. 'Las arenas’”,Sur, núm. 234, mayojunio.

»------- (1955). “Aventura y revolución peronista. Testimonio”, Contorno, núm. 7-8, julio.

"------- (1964). Buenos Aires, vida cotidiana y alienación, Buenos Aires, Siglo $X X$.

»----------- (1966). Eva Perón, ¿aventurera o militante?, Buenos Aires, Siglo XX.

»-------- (1971). Los oligarcas, Buenos Aires, CEAL. 

(1983). Los deseos imaginarios del peronismo, Buenos Aires, Legasa.

"----------- (2005). El tiempo de una vida. Autobiografía, Buenos Aires,Sudamericana.

»--------- (2008). Comediantes y mártires. Ensayos contra los mitos, Buenos Aires, Debate.

»--------- (2011). “Escrito en los márgenes”, adn Cultura (La Nación), núm. 204, julio.

»Sloterdijk, Peter (2002). El desprecio de las masas. Ensayo sobre las luchas culturales de la sociedad moderna, Valencia, Pre-Textos.

»Stéphane, Roger (1950). Portrait de l'aventurier. T. E. Lawrence, Malraux, Von Salomon, París, Sagittaire.

» Terán, Oscar (1991). Nuestros años sesentas. La formación de la nueva izquierda intelectual en Argentina 1956-1966, Buenos Aires, Puntosur.

» Vázquez, María Celia (2011). “Sur: peronismo y después”, en Intervenciones intelectuales en el contexto del peronismo clásico, Bahía Blanca, Editorial de Universidad Nacional del Sur.

»Vázquez, María Esther (1991). Victoria Ocampo, Buenos Aires, Planeta.

» Viñas, David (1965). “14 hipótesis de trabajo en torno a Eva Perón”, Marcha, núm. 1264, julio.

» ---------- (1965). “14 nuevas hipótesis de trabajo en torno a Eva Perón”, Marcha, núm. 1270 , setiembre. 
